\title{
Nasal resistance and OSA
}

Keywords: nasal resistance, osa, snoring.

Letters regarding the paper "Epidemiological study of the structural alterations present in the nasal cavity associated to the obstructive sleep apnea syndrome (OSAS)", published on the Brazilian Journal of Otorhinolaryngology 72 (4) July/ August 2006. Paper available at: http://www.rborl.org.br/conteudo/acervo/acervo_english.asp?id=3258

Murat Enoz', Mustafa Sitki Gozeler ${ }^{2}$ LETTER

Dear Editor,

Most studies of the pathophysiology of obstructive sleep apnea syndrome (OSA) have emphasized anatomical abnormalities of the oropharyngeal and hypopharyngeal airways. Yet the nose and its impact on snoring and OSAS have not been completely ignored.

Dr.Neto $^{(1)}$ and his friends emphasized that, structural alterations of the nasal cavity have high incidence in patients with OSA. These structural alterations such as septal deviation, conchal hypertrophy or others lead to obstruction of natural air flow and consequently increased nasal resistance.

Some studies reported that, nasal resistance has no impact on the pathogenesis of OSA. Thus, both snoring and sleep apnea are probably caused by other factors, such as restrictive processes in the pharyngeal area, rather than increased nasal resistance ${ }^{(2,3,4)}$.

Metes et al. did not find any effect on snoring, apneas, hypopneas or oxygen saturation in a small sample of patients, despite a reduction in nasal resistance ${ }^{(5)}$.

Nasal surgery for OSA usually has a very positive effect on improving the quality of life and CPAP tolerance in OSA patients ${ }^{(3,5)}$.

\section{REFERENCES}

1. Mekhitarian Neto L, Fava AS, Lopes HC, Stamm A. Epidemiological analysis of structural alterations of the nasal cavity associated with obstructive sleep apnea syndrome (OSA). Rev Bras Otorrinolaringol (Engl Ed). 2005 Jul-Aug;71(4):464-6.

2. Jessen M, Fryksmark U. Is there a relationship between the of nasal obstruction and snoring? Clin Otolaryngol 1993;18:485-7.

3. Kerr P, Millar T, Buckle P, Kryger M. The importance of nasal resistance in obstructive sleep apnea syndrome. J Otolaryngol 1992;21:189-95.

4. Miljeteig H, Hoffstein V, Cole P. The effect of unilateral and bilateral nasal obstruction on snoring and sleep apnea. Laryngoscope 1992;102:1150-2.

5. Metes A, Cole P, Hoffstein V, Miljeteig H. Nasal airway dilation and obstructed breathing in sleep. Laryngoscope 1992;102:1053-5.

'Dr. (Specialist)

${ }^{2}$ Dr. (Instructor in Department of Otolaryngology, Head \& Neck Surgery, Istanbul University, School of Medicine, Turkey)

Department of Otolaryngology, Head \& Neck Surgery, Istanbul University, School of Medicine, Turkey.

Corresponding author: Murat Enoz Address: Oruc Reis Mah. Albayrak.

Cad. No:59 34235 Esenler / Istanbul Turkey Phone: +905554293937 Fax: +902123439043 Email: muratenoz@yahoo.com We have not any financial disclosure

Paper submitted to the ABORL-CCF SGP (Management Publications System) on June 14th, 2006 and accepted for publication on August 10th, 2006. Cod. 2125.
Levon Mekbitarian Neto ${ }^{1}$ REPLY

I thank you for your interest and comment on my article posted on "Revista Brasileira de Otorrinoralingologia ".

The OSA has a variety of causes, with anatomic abnormalties on the oropharyngeal and hypopharyngeal airways. We believe that these abnormalties are caused by the oral respiration since childhood, causing proble$\mathrm{ms}$ in the tongue posture, abnormal deglutition, and bite alterations, with orthognatic and morphological facial alterations.

In our series of cases the structural alterations of the nasal cavity had high incidence in patients with OSA, although I did not state that this was an OSA cause, but we emphasized that these nasal abnormalties must be studied and corrected, whenever possible, to increase CPAP tolerance.

Sincerly, Levon Mekhitarian Neto
${ }^{1}$ Mestrando (sócio)

Paper submitted to the ABORL-CCF SGP (Management Publications System) on August 9th, 2006 and accepted for publication on August 10th, 2006. Cod. 3327. 